\title{
WHAT CAN MODES DO FOR (MODERATE) RELATIVISM?
}

François Recanati, Perspectival Thought: A Plea for (Moderate) Relativism, Oxford University Press, New York, 2007, 308 pp.

Teresa Marques LanCog Group, Centro de Filosofia da Universidade de Lisboa Logos Group, Universitat de Barcelona teresamarques@fl.ul.pt

\section{Background and Overview}

Truth in thought and language is a fundamental philosophical issue, and much of François Recanati's philosophical production has concerned problems that gravitate around it, as is again the case with his most recent book, Perspectival Thought: A Plea for (Moderate) Relativism. In the introduction (p. 7), ${ }^{1}$ Recanati lays down a conceptual map of the different ways a sentence may be context-sensitive; this provides an overview of Recanati's intended position within the contemporary debate on contextualism, to which most of his earlier work was devoted, and also shows how he places the debate on relativism within that broader scheme. According to Recanati, there are three forms of context-sensitivity: (i) indexicality, (ii) modulation, and (iii) circumstance-relativity. These are all, according to him, forms of semantic context-dependence. In the present book, Recanati defends a moderate version of the third and last type of context-dependence - circumstance relativity - that does not affect explicit content at all.

It is thought to be philosophical common sense that understanding what is said, or asserted, requires understanding what would have to be the case for the assertion to be true. Propositions are normally taken to be the contents of assertions and other speech acts, and are thought to be true or false only with respect to possible worlds. Prior, Kaplan and Lewis developed logic and semantic frameworks that expanded the normal relativization of truth to possible worlds to other parameters, for instance to times, places or individuals. In

\footnotetext{
${ }^{1}$ All references by page number only are to Recanati's Perspectival Thought.
} 
Perspectival Thought, François Recanati follows this tradition, and defends a version of circumstance-relativity, which he calls Strong Moderate Relativism (SMR henceforth). The book thus falls in place with a current relativistic trend in contemporary analytic philosophy, one that has been recently developed in different ways by people like Max Kölbel, Peter Lasersohn or John MacFarlane. The book in fact offers the reader the opportunity to become acquainted with some of the main positions within this debate, and with some other interestingly related views in the philosophy of language and mind, as it offers throughout very detailed overviews and discussions of some of the relevant literature.

Perspectival Thought has an unusual structural organization. It consists of three books, divided in eleven parts altogether, and each in very short chapters. Book I, "Moderate Relativism", describes the core of SMR, from the framework and its background, to the classical discussion over temporalism, and to two alternative frameworks within which to treat circumstance-relativity: either a Lewisian or a Kaplanian one. Recanati proposes to defend a Kaplanian framework, arguing for the existence of three levels of content: the invariant linguistic meaning of sentence types, the context-dependent explicit content of interpreted sentences in contexts - the lekton - and the complete truth-conditional propositional content. Book II, "Experience and Subjectivity" is devoted to issues in the philosophy of mind, in particular those related to situated thought and experience. Recanati draws a distinction that is meant to tip the balance in favor of the three levels of content approach, the distinction between mode and content. He does so by covering issues on perception, episodic memory, de se thoughts and immunity to error through misidentification, and the imagination. The discussion is rather thorough and detailed, and the main aim is to argue that, in the case of mental content as in the case of linguistic content, there is room for relativized propositions, corresponding to the explicit content of interpreted sentences. Modes are types of mental states, and Recanati's proposal is that modes fix which parameters in circumstances of evaluation are part of the complete truth-conditional content of a mental state. Book III, "Egocentricity and Beyond" recovers the issues on relativism left unsolved in Book I. Recanati argues that in the case of mental content, modes can shift the relevant index, and that in the case of linguistic content, there may be free shiftability of indices. Perspectival Thought is in effect an extended argument for the conclusion that subjects' intentions, mental states and cognitive situations can determine such parameters relevant for 
truth-evaluations; in this, Recanati departs from standard semantic frameworks like Lewis's or Kaplan's, where the relevant parameter or index is the index of the context.

I will critically discuss some aspects of Perspectival Thought, while offering a more detailed overview of the book. I suggest that the main aim Recanati proposes to achieve - that a moderate relativist should adopt a Kaplanian framework with three levels of content, rather than a Lewisian framework with only two- seems nonetheless insufficiently motivated, and the arguments offered do not settle the issue. I suggest furthermore that the claim that subjects' mental states and cognitive situations can determine parameters or indices in circumstances of evaluation, even though this claim is not set up as the main aim, is an original and very interesting contribution in the book. It is also an important one, since it sets further apart the radical from the moderate relativist, and it is relevant in the current relativism debate, where truth is deemed to be relative to parameters other than worlds, times, places and individuals. I will nonetheless also offer a few objections to some of the reasons Recanati puts forward in support of this latter claim; I will object in particular to those that depend on some considerations about psychological modes drawn from Book II.

\section{Circumstance Relativity}

Recanati draws in Part 1 a distinction between two principles that, according to him, underlie the idea of truth relativity, duality and distribution. Given duality, truth-values are the product of content and the circumstance against which content is evaluated. Given distribution, there are determinants of truth-values that may be either part of contents or part of circumstances of evaluation. It is this principle that makes, according to Recanati, a case for moderate relativism. The idea of distribution comes, for instance, from the work of Perry or Kaplan. ${ }^{2}$ For Perry, for example, we can distinguish between what

${ }^{2}$ Cf. Perry 1986 or Kaplan 1989. The so-called operator argument is put forward by Kaplan 1989 and Recanati takes it as inveighing for the distribution principle. Temporal operators can only operate over propositions that do not mention a time, and likewise for locational operators. We cannot meaningfully say "Everywhere it is raining here". The place cannot be part of the content if a locational operator is to prefix a given sentence. Nonetheless, there is a place that an utterance of (2) "It is raining" concerns. An operator just shifts the place with respect to which an embedded sentence is to be assessed, that is, it shifts the place of the index. If there is an indexical like "here" in the sentence, then the indexical freezes the place, and the operator cannot shift it. 
an utterance is about and what it concerns. An uttered sentence ${ }^{3}$ is about what is explicitly articulated in the content of the sentence uttered. Thus:

(1) It is raining here.

is about Barcelona, since I utter it in Barcelona. A place is explicitly required to be supplied in the sentence. It differs from

(2) It is raining.

In the second case, no place or time is explicitly mentioned in the sentence, and as such the utterance is not about Barcelona, but it nonetheless concerns it, since I speak in Barcelona (and intend to speak about it). To get a truth-value an utterance of (2) must concern the time and place of utterance (or some other intended by the speaker), even if it is not about it. So, as the argument goes, times and places can either be ingredients of the explicit content of an utterance of a sentence or an aspect of circumstances of evaluation.

There are some classical Fregean objections against relativized propositions, in particular against the idea that some propositional contents can be true at some times, false at others. Gareth Evans (1985), for instance, argued that the content of assertions and thoughts couldn't be semantically incomplete nor fail to settle determinate truth-conditions. Assertions and beliefs must have stable evaluations.

One way to resist Evans's challenge is a radical relativist one, advanced by MacFarlane, denying that assertions must have stable evaluations. The radical relativist is committed to there being the possibility that some assertions are such that nothing in the context of utterance or within a subject's cognitive reach settles once and for all whether the assertion is correct or incorrect. The truth-values of assertions may still vary with respect to different contexts of assessment, perspectives from which they are evaluated, even after all the required context-dependent and circumstance-relative parameters are settled.

This is not Recanati's position. Evans's challenge does not affect the moderate relativist like Recanati, because he agrees with Evans's Fregean point that an assertion's complete truth-conditional content,

\footnotetext{
${ }^{3}$ I use indiscriminately "uttered sentence" and "utterance". In places, I use only "sentence" and it should be clear, from context, whether I mean "uttered sentence" or "sentence type".
} 
covering both the explicitly articulated content and the circumstance with respect to which that content is to be evaluated, cannot fail to yield a stable truth-value. As becomes clear in the rest of the book, what is a distinctive feature of moderate relativist positions (like Recanati's here) is that it is some feature of the context of utterance, or of the context and the speaker's intentions and cognitive situation, that fixes the relevant parameter in the circumstance of evaluation which will complete the content of an assertion. Therefore, what is required for an assertion to be correct or incorrect is fixed in the context of utterance, even for the moderate relativist. This is a deep divergence with the radical relativist, for whom, as was said above, it may happen that nothing in the context of utterance or in the speaker's intentions and cognitive situation, settles the conditions of the truth or falsehood of an utterance. In Book I, Recanati does not make this difference sufficiently clear. Rather, he elucidates radical relativism just as a view on which complete contents can possibly have different evaluations in different situations; this is an elucidation of radical relativism from which MacFarlane himself appears to disagree, as his view is independent from whether contents are complete or not (cf. footnote 32 , p. 89).

Recanati's version of moderate relativism, SMR, is strong, he says, because even when an utterance has a complete explicit content, there is still a difference between the content expressed and the situation with respect to which the content is evaluated (p. 49). It is not very clear for the reader why this is a useful distinction to draw, however. Given how the radical relativist position was described, SMR does not seem to be very different from radical relativism. Yet, as a matter of fact, SMR is different from radical relativism because in SMR what is required for settling truth-values is fixed in the context of utterance. With this difference made clear, to say that there is a difference between a complete truth-conditional content and the situation that makes that content true or false does not seem to be a particularly relativistic claim to make. In effect, all truth-absolutists who hold that there are no relativized propositions distinguish between contents and the facts that make them true or false. It is no more than the principle of duality, whose endorsement is not sufficient for a position to be relativistic in any interesting sense. Nonetheless, I will continue to refer to Recanati's position on moderate relativism as "SMR"

Part 2 and 3 of Perspectival Thought are devoted to the temporalist debate. In the chapters comprising these two parts of the book, Recanati contrasts Prior's original tense-logic, where sentences are 
temporally neutral and tenses are handled through the introduction of temporal operators, with objections against it. ${ }^{4}$ The semantic alternative to treating tenses as operators is to explicitly quantify over times. Recanati assesses the arguments in this debate carefully. This debate prompts an important consideration, which is whether there are any deep conceptual reasons to prefer a tense-logical approach over an extensional quantificational approach, or whether the choice is merely pragmatic, a function of one's theoretical preferences. This is a recurrent worry in the book, and it affects the impact of its main goal - whether there are any compelling reasons to prefer a Kaplanian approach to a Lewisian one.

Recanati attempts an important step for the book's goal here. In the balance between the tense-logical and the extensional quantificational approach, Recanati appeals to some psychological considerations in favor of the tense-logical approach. Briefly, simple sentences that lack explicit modal or temporal operators, or indexicals, do not require that speakers be aware of the modal and temporal relativity of their utterances - that is, speakers may be unaware that what they say and think is true with respect to possibly different situations. This is referred to as temporal, locational or modal innocence. Recanati appeals to thought experiments about possible populations with simple languages devoid of modal and temporal terms, and who, as a consequence, fail to explicitly articulate in language (and presumably also in thought) the reference to specific parameters in the situations their utterances concern.

It seems doubtful, however, that semantically competent speakers can be as semantically naïve as Recanati portrays this community as being. Take locational relative utterances, and a sentence like:

\section{(3) John is sitting.}

There is here no explicit mention of a place, so no place is articulated (lexically). As the story goes, (3) is not about where John is sitting, but concerns it nonetheless. Certainly, no community of naïve speakers (admittedly naïve in many respects) would fail to think that John is sitting some place or other, just because their language lacks an indexical like "here" or "there". They would not think that John is sitting everywhere or nowhere, for instance. Again, these speakers certainly would not think that John is sitting all the time, and they would not always think that John is sitting, even if

\footnotetext{
${ }^{4}$ Developed by Partee 1973, Kamp 1971, or King 2003.
} 
they lack an indexical like "now". That the lack of an explicit term to refer to a parameter in a circumstance of evaluation should be taken as a reason not to endow speakers with the capacity to concern themselves knowledgeably, even if implicitly, with such parameters seems questionable for several reasons, not the least because demonstrative reference seems to be so basic in communication. It is one thing not to endow a community with the capacity to reflectively think or talk about something, it is quite another not to endow that community with the capacity to think or talk about something entirely.

Perhaps the modal case is less obvious at first sight, since we always speak in the actual world. But there is one more general worry, in particular concerning the modal case. Recanati alludes to it in a footnote acknowledging briefly a comment made to him by Robert Brandom. As he says: "According to some authors there is an implicit modal component in our simplest concepts, so the users of the language we are imagining should be said to lack the reflexive abilities necessary for explicitly thinking about modal issues" (footnote 22, p. 67). Now, the problem is not just that such speakers would not be capable of explicitly thinking of modal issues. As was mentioned earlier, understanding what is said requires understanding what would have to be the case for what is said to be true. Now, there are (at least) two important issues related to this. First, concept possession requires a capacity to abstract from particular instances of objects exemplifying particular properties. The so-called Generality Constraint ${ }^{5}$ says precisely that if one is capable of understanding $a$ is $G$, and $b$ is $F$, then one must also be capable of understanding $a$ is $F$ and $b$ is $G$. What is the relation? Possession of even the simpler concepts requires a capacity to foresee other ways things may be. It is hard to understand what kind of concept possession might be attributed to any subject who lacks such a capacity. Second, the development of possible world semantics, as the very idea of circumstance-relativity, is well-motivated because it rests on this: that understanding requires the capacity of abstracting and generalizing, that understanding requires grasping what truth would require, and that understanding is not by itself sufficient to know the truth (so, understanding that $a$ is $F$ is not sufficient to know whether it is true that $a$ is $F$ ). So, it does not seem that innocence arguments can be granted much strength, not even in the modal case. Overall, the choice between operators over explicit quantification remains a matter of theoretical taste.

${ }^{5}$ Cf. Evans 1982. 
The central question the book is concerned with, and the book's overall goal, is laid down in Part 4. Standardly, either in Lewisian or in Kaplanian frameworks, the index or circumstance parameter is by default the index of the context. That is, a sentence like (2) "It is raining" is evaluated with respect to the place, time and world of the context of utterance. Indices can be shifted by operators, locational, temporal or modal. But parameters can be frozen, by means of indexicals, like "here" or "now". In either Lewis's or Kaplan's frameworks, there are two types of dependence of truth-values on features of context: context-dependence and circumstance-, or as Lewis calls it, index-dependence.

On the Lewisian framework, the meaning assigned to a sentence is a complex function from context-index pairs to truth-values. So,

(1) It is raining here

is true with respect to context of utterance $c$ and index $i$ iff it is raining at place of $c$ at the time of $i$ in the world of $i$. Yet,

(2) It is raining

is true with respect to a context $c$ and index $i$ iff it is raining at the place, time and world of $i$. For Lewis, dependence of truth-value on the context of utterance is indexicality in the broad sense. It differs from indexicality in the strict sense, which is the result of freezing a parameter that cannot then be shifted by any operator. If no operators shift the index of the context, and no indexicals freeze a parameter in context, then the index is by default given by the context (cf. above footnote 2 on the operator argument, p. 79).

Recanati's SMR is a Kaplanian approach, distinguishing between three levels of content: (i) a context-independent meaning (Kaplan's character), which is a function from a context to a contextually variable lekton (Kaplan's relativized contents); (ii) the lekton is a relativized proposition, a function from circumstance/index/situation to truth-values; (iii) the complete content of an utterance (or of a mental state), the Austinian proposition, consisting of the lekton and the contextually relevant situation, which determines a classical proposition. ${ }^{6}$ It is more or less standardly acknowledged that either approach is interchangeable, the choice depending on one's theoretical preferences, even though there have been attempts to argue that either framework is preferable.

\footnotetext{
${ }^{6}$ The notion of an Austinian proposition was developed by Barwise and Etchmendy 1987.
} 
The contents of indexical belief display a similar duality to that of utterances, between the narrow content that plays a certain causalexplanatory role, and the truth-conditional object of belief. Take a classical example. Imagine someone thinks to herself with relief at the end of an exam "Thank goodness that's over". If the content of "that's over" were only "the exam finished at 3:00 pm, March 25, 2008, GMT", then we could not explain why the person was relieved to acknowledge the end of the exam at that time. She knew, presumably, that the exam would have finished by then long before the exam even started. But she was not relieved that the exam would have been finished by 3:00 pm, March 25, 2008, GMT. She was only relieved when the exam actually ended. So, "that's over" and "that's over at 3:00 pm, March 25, 2008, GMT" do not express the same narrow content, even though presumably both express the same truth-conditional content. Here is a different type of case, to the same effect: Suppose Holmes and Watson are sitting opposite each other at dinner table, and each thinks to himself "the salt is on the left", and each reaches to his left. Both think the same, in the narrow sense, and that explains why each reaches to his own left. Yet, one of them is right in so doing and the other is wrong, as one does reach the salt while the other does not. The causal explanatory role is played by a mental analogue of the linguistic meaning of the sentence "the salt is to the left", but the truth-conditional content, which in this case differs between them, explains why one reaches successfully for the salt and the other fails to do so.

Naturally, the question can arise as to why a third level of content is required for the explanation of belief states and attributions. The same doubts as to what substantial explanatory difference there is in the linguistic case can be raised with respect to the case of mental contents. Recanati recognizes the seriousness of the charge: "If relativized propositions are to be the objects of the attitudes, it is in the psychological sense; but in that sense there is a much better candidate for the status of psychological content, namely the meaning of the sentence-type" (p. 115). Recanati proposes to offer in the remaining of the book a good argument for the lekton.

\section{Content, Mode and Varieties of Perspectival Thoughts}

In Book II, Recanati covers extensively issues related to perspectival thought and first-person experience, introducing a distinction between mode and content. There is a parallel distinction between illocutionary force and content in discourse. Frege argued that it 
couldn't be part of the meaning of a sentence that it is an assertion, or any other type of speech act. The same sentence, without any change in meaning, can be used assertively or in a work of fiction, where it is not asserted. Therefore, that a sentence is used to make an assertion is not part of its meaning.

Recanati intends to account for the distinction between force and content within SMR and to use it to argue for his case:

Illocutionary force, in the SMR framework, is handled through the specification of the situation against which the utterance is meant to be evaluated. Just as an assertion that $p$ presents the fact that $p$ as holding in the actual world, a command that $p$ presents the fact that $p$ as holding in a situation the addressee is asked to actualize, that is, to bring about. A promise that $p$ is similar, with one difference: the actualizer is supposed to be the speaker, not the addressee. (p. 126, my emphasis)

There is one important aspect of the difference between force and content that Recanati does not mention, though, and that raises doubts as to how the mode, the psychological parallel to illocutionary force, is to function in the SMR framework, as it also raises doubts as to how illocutionary forces are to work. In a nutshell, it is an essential aspect of the difference between force and content that content is embeddable in logically more complex sentences. Logical relations hold between contents, contents are compositional, and this can be explained in terms of relations between the constituent parts of complex sentences. But illocutionary force is not embeddable. The classic Frege-Geach point (Frege 1984; Geach 1965) for the difference between force and content involves an example with an instance of modus ponens. For instance,

(4) If Recanati is French, then he is not Spanish.

(5) Recanati is French,

(6) so, Recanati is not Spanish.

We can infer (6) from the assertion of (4) and of (5). The content of the antecedent of (4), and that of (5) must nonetheless be the same, for on it rests the validity of the argument. But since when I merely assert (4) I do not assert its antecedent, it follows that assertoric force cannot be part of the content of the sentence "Recanati is French", and it cannot be embeddable nor stand in logical relations holding 
between contents. The Frege-Geach point has been used in the analytic tradition not only for the separation of illocutionary force and propositional content, but also against some positions that purport to make force do some of the work done by content, for instance, some simple versions of expressivism in ethics or aesthetics. Curiously, the problem Recanati's version of SMR has to do, I believe, with this too.

Recanati rejects a view of Searle's 1969, that certain types of illocutionary force can only take as contents certain types of propositions. For instance, that a promise can only take as content a proposition in the future tense. Recanati accuses Searle of committing a fallacy of misplaced information, i.e., of placing in the content features that belong to some feature of the illocutionary force: "a common mistake, which consists in ascribing to the propositional content of a speech act a property that is actually a feature of its illocutionary force" (p. 127). The fallacy consists, Recanati says, in putting in the content of certain types of speech acts aspects that belong properly to the illocutionary force. It may be that Searle's view is misleading, or not entirely well formulated, but Searle can be plausibly understood as saying that some types of illocutionary force place constraints on the type of content some speech acts can correctly take - i.e., different types of illocutionary acts have distinct correctness conditions. For instance, a promise can only be correctly made if the content of the promise is in the first person and in the future tense.

As Recanati puts forward his view, however, it also seems to be misleading. Suppose that we take the claim that "illocutionary force is handled through the specification of the situation against which the utterance is meant to be evaluated" as saying that the specification of the situation defines, or offers an analysis of, a type of illocutionary force. Take the case of assertion in particular, "an assertion that $p$ presents the fact that $p$ as holding in the actual world". One problem with this view on illocutionary force is that specifying the situation against which a situation is to be evaluated is neither sufficient nor necessary to individuate illocutionary force. If we specify possible world, time, agent and place, we still have not identified which speech act is performed. One might be asserting, betting, supposing, conjecturing, predicting or warning that $p$, while concerning a very specific given situation (and it might even be true that $p$ ). So, specifying the situation, by itself, is not sufficient to individuate a given type of illocutionary force.

On the other hand, knowing which speech act is performed does not tell us which situation the speaker concerns. In particular, assuming that propositional truth is indeed relative to more than the actual 
world, knowing that a speech act is an assertion does not start to tell us which situation is concerned (not the time, for instance), since any propositional content, relativized or complete, can in principle be the content of an assertion. So, the specification of the situation is also not necessary to individuate a speech act, at least assertion. If Recanati were right, however, whenever the wrong situation was concerned, one would fail to perform the (intended?) speech act, rather than doing so incorrectly. To illustrate what is wrong with this idea, here is a true anecdote. There was a mother who promised to the Virgin of Fatima that if her son survived the colonial war, then he would go on his knees to Fatima. That is an incorrect promise to make, and a good account of illocutionary force should explain why it is incorrect. The right prediction seems to be that she violated a correctness condition of promises - she had no right to make that promise in the first place.

I suppose Recanati could be satisfied with casting his comment that "force corresponds to the type of situation with respect to which the lekton is supposed to be evaluated" (p. 128), as saying that illocutionary force imposes constraints on admissible contents, and not as saying that some parameters of situations actually belong on the side of illocutionary force. Unfortunately, Recanati explicitly rejects this hypothesis (p. 133).

The general problem relates to the Frege-Geach point and to what situations are, in particular to the force/content distinction and to the fact that a situation concerned is, in some sense, on the side of content. One might learn that $p$ from someone's assertion, and draw inferences from $p$. When $p$ is embedded and further considered, for instance, in a conditional, the situation concerned must be the same as that of the original assertion, but the conditional assertion, if $p$, then $q$, might have an antecedent concerned with a past situation (the same as the assertion that $p$ ) and a consequent concerned with a future situation. So there is no such thing as, or at least there need not be, the time an assertion of a conditional concerns. But both antecedent and consequent concern particular moments of time. The moment of time must be available independently of the speech act performed, and must be part of content. Therefore, the situation concerned, insofar as it is relevant for the truth-conditional content conveyed, cannot depend exclusively on the initial speech act performed.

This limits, I think, the possibility of success of Recanati's account of illocutionary force and also of psychological modes achieving what SMR requires of them. What is part of content - complete or 
otherwise - must be available as such. Contents must be preserved under embeddings, and that means that they must be available independently of particular illocutionary forces or psychological modes.

Perhaps the problem is not only Recanati's, but is a problem for anyone who distinguishes between what a speech act is about and what it concerns. And, to be fair, it may be that this is not an insurmountable difficulty for Recanati's proposal. His framework could accommodate a detailed account of how different modes or forces coordinate the preservation of the relevant times, places, agents, etc., that are needed to track the complete Austinian proposition in sound reasoning processes, one that takes into account the worry in the Frege-Geach point.

Now, modes are the psychological type of state or act parallel to illocutionary force. Types of modes are, for instance, perception, memory, imagination or belief. In the case of the psychological mode, as in the case of illocutionary force, Recanati wants to reject accounts that place in the content - at least in the lekton - some features required for the correctness of the mental state. Recanati illustrates the type of rejected account again with Searle's views on visual perception. He uses capital letters to indicate the mode of visual experience:

VIS EXP (that there is a flower there)

This contrasts with Searle's representation of the content of the visual experience:

VIS EXP (that there is a flower there and that there is a flower there is causing this visual experience)

On Searle's view, the content of the visual experience includes a reflexive component that makes reference to the visual experience itself, requiring there to be a flower causing that very same visual experience. The visual experience is "incorrect" if there is no flower causing it, and that is the reason why Searle makes the reflexive constraint be part of the correctness conditions of the visual experience, and hence, part of the content of the experience. One could, after all, have a visual experience of a flower there while being under an optical illusion, and thus there being no flower causing the visual experience.

Recanati, however, argues that the reflexive condition is not part of propositional content of the visual experience (of the relativized proposition, which, according to him, is the content of the visual 
experience). The subject does not see the causal relation, what he sees is the flower in a particular location. This is an important point that reveals why it is that Recanati believes we need a lekton. The lekton is something that goes beyond the plain linguistic meaning or narrow content, and includes some aspects of external circumstances, in particular those the subject is immediately and consciously aware of - in this case, that there is a flower there - and in general those that are (or can be) explicitly verbally articulated.

A causal relation, allegedly, is not available, so it is not part of content. Yet, it must somehow be determined or settled by the psychological conditions of a subject, on Recanati's view, by the mode of visual experience; "that there is a flower there and that there is a flower there is causing this visual experience" corresponds to the Austinian proposition, the complete content:

That the state of affairs represented (there being a flower there) causes the representation of that state of affairs is a condition that has to be met for the representation in question to count as a perception (rather than, say, an expectation). It follows that the self-referential condition is determined by the perceptual mode of the state, not by its content. For a representation that $p$ to count as a perception that $p$, it must be the case that the representation is caused by the fact that $p$; but what is represented is only the fact that $p$. In other words: the content of the state (viz. the proposition that $p$ ) only determines the self-referential condition. Together, the content and the mode determine the overall truth-conditions of the state. (pp. 131-132)

Recanati here speaks of perception and of conditions that must be satisfied for a state to be a perception. This model of how modes determine full contents is to be generalized to other types of mental states and contents. Recanati contrasts the mode of visual experience with the mode of episodic memory to further illustrate the model. A subject's episodic memory shares with the visual experience only the lekton that there is a flower there, but the time of the circumstance of evaluation differs. It is the memory mode that determines that the time is past, where the perception determines that the time is present.

But it is not entirely clear how modes are supposed to work here. First, even if "the subject is aware of the perceptual nature of his experience" (p. 133), he might not be aware of being under an illusion; a subject under an illusion of a present flower can try to pick a flower in very much the same way as a subject who actually sees a flower. But if a subject remembers, expects, or imagines, 
a flower there, she does not act in the same way as a subject who is under the illusion of a flower there. So far, the only common content in all these cases is the lekton. The lekton must perform, at least, as much in explaining behavior as narrow contents do. But it seems moreover, from Recanati's remarks above, that modes must also play a role in the explanation of behavior. Either there is more in common than the lekton between the content of a visual perception and a visual illusion that explains the same behavior, or there is more in common between the visual mode and the visual illusion that explains the same behavior. The last option requires that modes do a substantial part of the explanatory work.

Overall, it is not clear how the visual mode fixes such things as the existence of an appropriate causal relation between the occurrence of the mode itself and what is represented. Maybe Recanati could further complete his account with some evolutionary explanation of how the cognitive system works, or with some alternative causal covariational story. ${ }^{7}$

A distinct and more serious worry is how, in Recanati's account, memories and perceptions justify the acquisition of belief, in particular how the content of perception and memory can be inferentially preserved through sound inferences to belief and knowledge. The issue is again related to the earlier concerns of embeddability of contents and the Frege-Geach point. Imagine the following case. You remember that Peter was at the party. You know that Peter and Paul are always together. So, you think, if Peter was at the party, Paul was at the party. You thus infer on the basis of your memory that Paul was at the party. It is unclear how the formation of beliefs, directly on the basis of memory or of perception, or indirectly through inference, can nonetheless concern the same past time as the memory that Peter was at the party, when no memory is part of the content of the conditional 'if Peter was at the party, then Paul was at the party', and you do not remember that Paul was at the party, so that is not what grounds your belief that he was. It seems that this kind of problem arises again because Recanati makes the determination of content that must be independently accessible for valid and sound reasoning, depend on particular psychological modes that are actually entertained by agents. Particular psychological modes, or illocutionary forces, are not embeddable; it would appear that only lekta are embeddable, on Recanati's account, and thus it would seem that the

${ }^{7}$ I owe this suggestion to an anonymous referee for this journal. 
framework of SMR should, at the very least, be supplemented with a substantial account of how psychological states and speech acts can keep track of the same complete Austinian proposition in inferences.

A substantial part of Perspectival Thought (Parts 6, 7 and 8) is devoted to the self and de se thoughts. This is a relevant topic for relativism insofar as it concerns mental contents that are contextdependent and circumstance-relative. The relevance in the overall argument for the main claim in the book - that we need an intermediate notion of content like the lekton - is not clear at a first reading. The discussion is nonetheless interesting and detailed, it engages with the classic literature on the topic, from the work of Perry and Shoemaker to that of Lewis and Higginbotham. Two issues seem more relevant for the overall aim of the book. One is the problem of immunity to error through misidentification, and the other the reflexivity of de se thoughts.

Recanati distinguishes between implicit and explicit de se thoughts:

An explicit de se thought is a thought the (explicit) content of which involves an "identification component" through which the object thought about is identified as oneself. The subject who sees himself in the mirror and thinks "My legs are crossed" entertains such a thought, and explicitly thinks of the person whose legs are crossed as being herself. [...] Here the concept EGO occurs on the side of the lekton $[\ldots]$. In contrast, implicit de se thoughts are identification-free $[\ldots]$. The lekton is a personal proposition, without any constituent corresponding to the person to whom a property is ascribed. (p. 176)

The way Recanati handles de se thoughts echoes earlier discussions where he distinguished what is explicitly articulated in an utterance of a sentence and what that utterance requires for truth. De se thoughts are reflexively about (or concern) the person who entertains the thought itself. The main difference between the implicit and explicit de se thoughts depends on whether the subject explicitly represents herself in thought or not. In the explicit de se thought, the subject thinks, while seeing herself in the mirror, "My legs are crossed". In contrast, when she makes a perceptual judgment "there is a flower there", the complete content is something like there is a flower at the place and time of perception, and that there is a flower there is what causes (in the right way) my perceptual judgment that there is a flower there. The subject, as well as the time and place of the perception, are part of the complete content of the perceptual 
judgment, even if not explicitly articulated in the content of the perceptual judgment. The judgment, like all her other thoughts, is implicitly de se, since it is of the subject. If true, it is true at the subject. De se thoughts are, in any case, distinct from de re thoughts about oneself (contrast with a subject looking in the mirror and thinking: "her legs are crossed").

Implicit de se thoughts are immune to error through misidentification. Whereas a subject seeing someone reflected in a mirror and judging "My legs are crossed" might have failed to identify herself, because it is not her who is reflected in the mirror, in the implicit case it is not possible to be in error as to who is having the thought episode. The thought is true at the subject, so to speak, and the reflexivity - that the thought is to be true at oneself - is determined, according to Recanati, by the psychological mode, it is not what the subject thinks — at least, not explicitly. Here, the argument rests once more on claims made earlier in the book. As the subject does not explicitly refer to herself in thought, the self-reference cannot be part of the lekton that is the content of the de se thought,.

There are accounts of de se thoughts, and of immunity to error through misidentification, which do not posit an intermediate level of content like the lekton. One such account is Higginbotham's, which is a reflexivist account. On the reflexivist account, there is simply a narrow content that is self-ascribed. So, if the subject sees a flower, the content of her experience is that the subject of this visual experience sees a flower. She cannot fail to identify herself as the subject of the state as she is herself the subject of that state. There is no need, on these accounts, to postulate an intermediate level of content between the narrow content that plays the required causal explanatory work, and the complete content of the experience or thought event.

Yet, Recanati rejects reflexivist accounts. Recanati claims that placing a reflexive constraint in the content of the thought is not sufficient to explain de se thoughts. More is needed, as the state must not only be reflexive, as the subject must also be fully and consciously aware that the state is her own. Reflexivism fails to take into account the requirement that the subject must (i) be in a conscious state (the subject must be experientially aware of the state), (ii) selfascribe the state and (iii) be aware that she is presently experiencing that state (p. 182). But if the account presupposes the conscious selfascription of the reflexive state, then the analysis is superfluous, as it is not explaining what is genuinely de se in the mental state, i.e., 
how a subject is consciously self-ascribing a reflexive state. This is illustrated with an example. Imagine a schizophrenic patient who entertains some thoughts which she thinks are not her own, or believes those thoughts were planted in her mind by "The Other" or her psychiatrist, but are thoughts thought by the psychiatrist (p. 183), for instance the thought "I am good and omnipotent". This is a counterexample to reflexivism because the subject is aware of the state, and of presently experiencing it, but does not self-ascribe it. She judges that whoever planted the thought in her mind judges that he himself is good and omnipotent. So the state is reflexive, but that it is so is not sufficient to account for why the thought is de se.

However, it is not clear that Recanati avoids the problem he accuses the reflexivist of having. If it is true, as Recanati says, that what is part of the lekton is what is explicitly articulated, and that the reflexive condition is on the situation side of the complete content of the mental state, but is not something of which the subject need be reflectively aware, then it seems that the schizophrenic counterexample should be as much a problem for Recanati's view as for the reflexivist. We are still in the dark as to what makes it the case that by thinking certain thoughts one thereby thinks of oneself. And it is also unclear how this establishes that, because of self-referential thoughts, we need an intermediate level of content like the lekton. It does not seem that Recanati can claim an advantage over his reflexivist opponent, nor claim that the objection above plays any role in justifying the lekton. Recanati can claim that it is the mode of the de se thought that makes a subject self-ascribe a state. But further argument is still in need.

Overall, the same sort of worries that arise with the general framework of SMR, and with the arguments given in support of the lekton, arise also in this particular case. The requirement of contents that play some causal-explanatory role seems to be met by the lekton as much and to the same extent as they are played by narrow contents. Appealing to what subjects are explicitly and immediately aware of is not conclusive either way. If conditions like reflexivity are part of the situation side of content, and as such are possibly inaccessible for the subject who entertains merely the lekton, then we cannot explain subjects' behavior, which involves de se attitudes, adequately. Moreover, by saying that modes are what fix the relevant aspects of the complete contents does not start to tell us how modes do so. 


\section{Final Concerns: Assessing the Case for Moderate Relativism and the Lekton}

The final Book of Perspectival Thought brings together the discussion on situated mental content and experience in the previous sections with the motivation and overall arguments for SMR. Recanati recovers the central question:

what reason can we have for insisting that the lekton must be contextdependent (in the manner of Kaplan's "contents"), hence not purely psychological? [...] Rather than equate the lekton/situation distinction with that between purely psychological and environmental determinants of truth-value, as Lewis does, I suggest that we align it with the distinction between content and mode, presented and elaborated in Book II. This is most natural since, as we have seen the mode fixes the situation of evaluation, and thereby determines aspects of the complete content that are not articulated in the representation, hence that are not part of its explicit content. (pp. 215-216)

Unfortunately, as the worries from the previous sections have shown, it is not clear how modes fix situations, as it is not clear whether they should do so in the first place. Moreover, the only plausible reason to recognize that there is an intermediate level of content between narrow psychological contents and environmental determinants of truth-value is that there are usually aspects of a situation that are explicitly acknowledged or consciously and immediately articulated by the subject. The question is whether these aspects require theoretically an extra level of content at all. In the linguistic case, it was clear there was no need to choose the Kaplanian approach over the Lewisian. So far, psychological modes have not pushed us in that direction either.

Book III is composed of three parts. Part 9 attempts to close the case for the existence of context-dependent lekta, and argues furthermore that any unarticulated elements of truth-conditional content must be placed on the side of the situation, rather than in the lekton. Part 10 returns to self-relative thoughts, and finally Part 11 is devoted to the issue of shiftability of indices or parameters in situations of evaluation. I will skip the discussion of self-relative thoughts, as I have said enough on why I think Recanati faces difficulties concerning this issue, and I will be brief on the discussion over unarticulated constituents. I will focus on two aspects of the final Book.

As mentioned in earlier sections, Recanati endorses a distinction that John Perry makes between what an utterance (or mental state) is 
about and what it concerns. Drawing this distinction makes it possible to distinguish also between what is explicitly articulated semantically in a sentence and what is not so articulated but is in any case part of the overall truth-conditions of an utterance of a sentence (and similarly for mental contents). As Recanati admits, illustrating the discussion with the case of seeing a swimmer crying for help,

Of course, it is open to us to say, with Lewis, that in the visual case just as in the imagination case, the lekton should only include the purely psychological content of the representation: a representation of a swimmer standing in a certain contextual relation to us, and crying for help. Since the identity of the swimmer is fixed by the situation $[\ldots]$, it should not figure in the content, on the Lewisian view. I grant that this is a perfectly coherent position to take, but there is an alternative position which is no less coherent: we may construe the perceived scene as a state of affairs in the world, with a real individual as constituent (the swimmer whose identity depends in part upon the context), and still distinguish that scene and its constituents from the elements that are not constituents of the scene, but only come into the picture via the situation of evaluation as determined by the mode. (p. 217)

This restates, for the case of mental content, the Kaplanian position with respect to the linguistic case that Recanati wants to endorse. But it is not a further argument for the existence of the lekton. The remaining of Part 9 offers reasons against placing on the mental or psychological side of content aspects of content that, as Recanati sees it, are properly parts of situations. This discussion is directed against treating some aspects of situations as unarticulated constituents of psychological or linguistic content, in particular against Perry's 1986 claim that not all instances of inarticulateness can be handled in terms of relativized propositions and the concerning relation. Perry seemed to hold that a proposition is relativized only when the situation it concerns (place, time, world, etc.) is simply that of the context of utterance (or of occurrence of a mental state), and subjects do not think reflectively about the situation concerned. Yet, whenever subjects" cognitive situation, beliefs and intentions play a "coordinating role" (p. 223) in settling the unarticulated parameter, then the relevant parameter is an unarticulated constituent of content. Recanati discusses and criticizes this position in considerable detail. I will not consider the discussion, as its focus is lateral to the central question of whether there is any substantial reason, other than a coherent theoretical preference, for admitting the existence of context-dependent lekta. 
The discussion relates however to the last topic of Perspectival Thought, the question of what can shift indices in points or situations of evaluation. Here, Recanati offers what seems to be an original view. Recanati departs, on the one hand, from Lewis's and Kaplan's orthodoxy - that the index in a situation is the index of the context of utterance, unless it is frozen by an indexical or shifted by an operator. This may be designated as the "Generalized Reflexive Constraint" (GRC). According to GRC, the content of a state or utterance must be evaluated against a situation that includes not only the subject, but also the time, place, world, etc., of the state or context of utterance. Recanati argues that indices can be shifted without operators, either freely in discourse, or by modes. An example of what illustrates free shiftability is the following. Imagine hearer and speaker are involved in a conversation about a place $l$ that is distinct from the location where the conversation is taking place, even though both interlocutors are talking about the state of the weather at $l$. If the speaker says "It's raining", according to Recanati, the speaker is not explicitly talking about place $l$, although the conversation concerns $l$. The speaker is not, contra Lewis, talking about the place of the context. So, Recanati concludes, in discourse indices can be shifted freely. Presumably, because of cases of mental states like memories or perceptions, Recanati introduces also the notion of mode-shiftability, as his claims in Book II require that modes shift indices (a memory mode shifts the time index of a perception mode, for instance).

Recanati also departs from Perry's view (presented in Part 9) that if a subject is reflectively aware of relevant parameters, times, places, etc., then these are unarticulated constituents of content, rather than indices in situations. On Perry's view, a subject's beliefs and intentions play a coordinating role in fixing these parameters. Recanati had argued in Part 9 that Perry does not provide good reasons against placing these parameters in the situation, and so rejects the idea that such parameters are unarticulated constituents of content.

The discussion of what settles relevant indices or parameters in situations is a complex and difficult one, and I will not dwell on it further. It is an important discussion that has perhaps not been carried out in as much depth as the current debate on moderate relativism would require. We need only remember that modern versions of relativism include further indices or parameters in situations of evaluation, in particular standards of taste, epistemic standards of justification, moral or aesthetic parameters, etc. It is not entirely 
clear how, once we depart from standard indices like places, speakers, times and worlds, the Generalized Reflexivity Constraint could be enforced. So, a fresh approach on this issue is definitely required, and it is a credit to Recanati that he attempts to offer an answer that can be applied to the current debate on relativism with its new variety of parameters on offer.

I have raised doubts, nonetheless, as to whether the idea of modeshiftability, or free shiftability, can be made to work as presented in Perspectival Thought. There is at least room for reasonable doubt, given the worries expressed in the previous section. The main worries are, first, that saying that modes are what fix the relevant aspects of complete content does not start to tell us how modes do so, and, second, given that we must preserve content (including aspects of the situation) under embeddings - i.e., the complete content of the thought/experience/speech act must be preserved under embedding when the relevant thought/experience/speech act does not occur- it seems that an account of the functioning of modes as Recanati's faces a serious challenge.

In any case, Recanati's Perspectival Thought is a challenging and ambitious book, covering a wide spectrum of issues; it dares to bring together different (only) apparently unrelated problems, from the philosophy of language to the philosophy of mind, giving us a much broader overview of what a full discussion of relativism and perspectival thought requires than is usually attempted in the current literature. It is very likely that many of the issues here considered will continue to be central topics in the philosophy of language and the philosophy of mind for years to come. ${ }^{8}$

\section{REFERENCES}

Austin, J.L., 1971, Philosophical Papers, 2nd ed., Clarendon Press, Oxford. Barwise, J., 1989, The Situation in Logic, CSLI Publications, Stanford.

Barwise, J. and J. Perry, 1983, Situations and Attitudes, The MIT Press/Bradford Books, Cambridge, Mass.

Barwise, J. and J. Etchmendy, 1987, The Liar: An Essay on Truth and Circularity, Oxford University Press, New York.

\footnotetext{
${ }^{8}$ Work supported by research fellowship SFRH/BPD/35825/2007 from the Portuguese Fundação para a Ciência e a Tecnologia, and by DGI, Spanish Government, research project HUM2006-08236 (C-Consolider). I am grateful to Manuel García-Carpintero and to Jonas Åkerman and to two anonymous referees for this journal for helpful discussion of some topics in this review.
} 
Evans, G., 1985, "Does Tense Logic Rest on a Mistake?", in G. Evans, Collected Papers Clarendon Press, Oxford, pp. 343-363.

- - 1982, The Varieties of Reference, ed. John McDowell, Clarendon Press, Oxford.

Frege, G., 1984, "Logical Investigations, Part II Negation", in Brian MacGuiness (ed.), Collected Papers, Basil Blackwell, Oxford, pp. 373389.

Geach, P., 1965, “Assertion”, Philosophical Review, vol. 74, no. 4, pp. 449465.

—, 1960, "Ascriptivism”, Philosophical Review, vol. 69, no. 2, pp. 221225.

Higginbotham, J., 2003. "Remembering, Imagining and the First Person", in A. Barber (ed.), Epistemology of Language, Oxford University Press, Oxford, pp. 496-533.

Kaplan, D., 1989, "Demonstratives”, in J. Almog, J. Perry and H. Wettstein (eds.), Themes from Kaplan, Oxford University Press, Oxford, pp. 481563.

Kamp, H., 1971, "Formal Properties of 'Now"', Theoria, vol. 37, pp. 227273.

King, J., 2003, "Tense, Modality and Semantic Values", Philosophical Perspectives, vol. 17, pp. 195-245.

Kölbel, M., 2002, Truth without Objectivity, Routledge, London.

Lasersohn, P., 2005, “Context-Dependence, Disagreement and Predicates of Personal Taste", Linguistics and Philosophy, vol. 28, pp. 643-686.

Lewis, D., 1998, Papers in Philosophical Logic, Cambridge University Press, Cambridge.

—- 1980, "Index, Context and Content", in S. Janger and S. Öhman (eds.), Philosophy and Grammar, Reidel, Dordrecht, pp. 79-100. (Reprinted in Lewis 1998, pp. 21-44.)

MacFarlane, J., 2005, "Making Sense of Relative Truth", Proceedings of the Aristotelian Society, vol. 105, pp. 321-336.

- 2003, "Future Contingents and Relative Truth", Philosophical Quarterly, vol. 53, pp. 321-336.

Partee, B., 1973, "Some Structural Analogies between Tenses and Pronouns in English", Journal of Philosophy, vol. 70, pp. 601-607.

Perry, J., 1993, The Problem of the Essential Indexical and Other Essays, Oxford University Press, New York.

- - 1986, "Thought Without Representation", Proceedings of the Aristotelian Society, suppl. vol. 60, pp. 333-361. (Reprinted in Perry 1993, pp. 205-219.)

— , 1979, "The Problem of the Essential Indexical", Noûs, vol. 13, pp. 3-21. (Reprinted in Perry 1993, pp. 33-52.)

Prior, A., 1967, Past, Present and Future, Clarendon Press, Oxford.

Prior, A., and K. Fine, 1977, Worlds, Times and Selves, Duckworth, London. 
Recanati, F., 2007, Perspectival Thought, Oxford University Press, Oxford. —_, 2004, Literal Meaning, Cambridge University Press, Cambridge. Searle, J., 1983, Intentionality, Cambridge University Press, Cambridge. ——, 1969, Speech Acts, Cambridge University Press, Cambridge.

Shoemaker, S., 1996, The First-Person Perspective and Other Essays, Cambridge University Press, Cambridge.

Stalnaker, R., 2003, Ways the World Might Be: Metaphysical and AntiMetaphysical Essays, Clarendon Press, Oxford.

Received: January 20, 2009; revised: August 21, 2009; accepted: February 17, 2010. 